\title{
XENOPHOBIA AND ITS IMPLICATIONS FOR SOCIAL ORDER IN AFRICA \\ DOI: http://dx.doi.org/10.4314/ft.v5i1.3
}

\author{
Bolatito A. LANRE-ABASS, Ph.D and Matthew E. OGUH, MA \\ Department of Philosophy, University of Ibadan
}

\begin{abstract}
Xenophobia, a form of discrimination practiced in countries, particularly in South Africa, is one of the major challenges confronting the modern day society. This paper examines xenophobia as a menace showing at the same time that this discriminatory practice bifurcates societies by creating a dichotomy amidst the various occupants of the society, thereby giving room for "otherness" rather than "orderliness". The paper also highlights the philosophical implications of this societal bifurcation, particularly to the human community. Seeking a plausible way of addressing this challenge, the paper concludes by emphasizing the relevance of the value of tolerance in curbing xenophobia.
\end{abstract}

Keywords: Xenophobia, Social discrimination, Tolerance, order and other, Africa.

\section{Introduction}

A basic plague that befalls some contemporary African societies is the monster called Xenophobia, which has as its features, discrimination and segregation and killing of non- members. As a result of this practice, any affected human society attempt to cut off setting portion of occupants for preserving them as the "other". Thus, "otherness" rather than orderliness becomes a factor in some societies today. Most disheartening is the fact that it now seems immaterial whether these societies belong to the developed or third world countries as could be seen in the case of countries such as South African and Greece. In some African societies however, there abound fragments of the act of discrimination in almost all human societies within Africa, even though the gravity of its perpetuation varies from one country to another (MCKINLEY, ROBBINSON, and SOMAVIA 2001, 2-4).

However, the aforementioned features of xenophobia, manifest themselves through different channels, such as social discrimination, gender discrimination, economic discrimination and even ethnic discrimination, which has being witnessed at one stage or the other in the course of human history (MCKINLEY, ROBBINSON, and SOMAVIA 2001,4). A common denominator amidst these various discriminatory tendencies is the fact that they all tend to present a picture of a bifurcated society, a society that consist of two factions, namely, the "we" and the "them". The "we" are those individuals that could otherwise be known as the natives, ofthey are those individuals that are always seen as the original inhabitants of any

society, while the "them" are those individuals, who are otherwise seen as strangers or simply put, the "other." 
The task of this paper is to seek a plausible avenue of creating a more inclusive society for all Africans, wherein various individuals would be at home with one another no matter the geographical location within the continent that they find themselves. To this end, this paper, tries to argue that structuring our relation with the "other" on the template of discrimination would be to have a biased conception of one of the essences of society, which is to create a safe habitation for all. This task can only be achieved when individuals across societies begin to imbibe the culture of tolerance not only for themselves but also for the "other". Consequently, the paper contends, that tolerance is a viable solution to the plague of Xenophobia and other forms of social discrimination that is recurrent in Africa. Again, it argues that this remedy can help reduce the adverse effect that Xenophobia could have on the Africa continent.

\section{Xenophobia: A Conceptual Analysis}

Etymologically the term xenophobic is derived from two Greek words, namely evoç(Xenos) meaning foreigner and $\varphi$ ßoc(Phobos) meaning fear (OKSANA 2009, 33-36). Hence, the amalgamation of these Greek words to produce xenophobos, otherwise translated as xenophobia. Xenophobia has been defined by Reynold Falger and Ian Vine as a psychological state of hostility or fear towards outsiders (REYNOLD and VINE 1987, 20). Similarly, Oksana Yakusho holds that xenophobia is a form of attitudinal, affective and behavioral prejudices towards immigrants, and those perceived as foreign (OKSANA 2009, 33-36). Also for Boehnke Klaude, xenophobia is an attitudinal orientation of hostility against nonnatives in a given population (BOEHNKE 2001, 21-23). From the foregoing definitions, xenophobic practices involve intense, unreserved fear and hatred for strangers. The discourse of xenophobia centres around the identification of the context wherein the term stranger is used, because the meaningfulness of the term is predicated on the supposed meaning of who a stranger is, as it is this "stranger" that is usually the agent that receives all the inhuman treatment that is meted on them (OKSANA 2009, 33-36). In view of recent happenings across the world, particularly that of early 2015, in South Africa, it became clear to the world that xenophobia is, armed with a lot of discriminatory tendencies that could cause social disorder and civil unrest in any country. Xenophobic violence, which is the violence that is carried out against an individual simply because he is a stranger, has a way of creating social unrest among the occupants of any country. Thus, xenophobia has economic, social and political causes (REYNOLD and VINE 1987, 20).

It suffices to state that economic hardship is one of the predominant factors responsible for xenophobic practices. As it is quite clear that increase in poverty level in most African states, with a correspondent drastic reduction in housing, Memployment, education, health care and even social welfare, are signals that the ofeconomy of those nations is dangling. These are a major factor that usually ignites

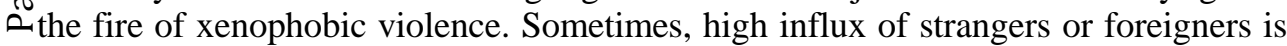
held accountable for this plight. This was well argued by Jonathan Crush when he 
maintained that economic imbalance pulls individuals into keeping available scarce resources to themselves and not wanting to share with others (CRUSH 2014, 25). The implication of this is that the stranger becomes vulnerable to not just xenophobic practices, but all other forms of "hate crimes."

It is important to note that the negative view of the "other" emerged from fears of diminishing economic resources, rapid demographic changes and diminishing political interest. (SUAREZ-OROZCO 2005, 121) This situation was exemplified by the 2015, incident of xenophobia in South Africa, where human lives and properties worth millions of dollars were destroyed by certain South Africans due to a reported statement credited to King Goodwill Zwelithni of the Zulu Clan in South Africa, where he ordered all foreigners to leave their land, because they have taken over the jobs that was meant for South Africans (ZWELITHINI 2015, NP). This create an impression that seems to suggest that individuals who are seen as strangers are a separate set of people from the Zulus in South Africa.

Another plausible cause of xenophobia, which is also one of the problems attributed to it, is the way man has conceived the social relation with the "other. The point is, man's social relation with his fellow seems to present the picture of being self-centred, hence, having no space for the accommodation of the other. This description, actually shows the true state of the human agent, who at the slightest spark of threat to his existence, would do everything including destroying the "other" to retain his existence. Consequently, there is a social connection between the way man thinks and how they relate with the "other", as they tend to give room for their cultural cognition as well as ethnicity in the formation of the knowledge about the "other". Thus, this existing social relation amidst the members of a society accounts for why xenophobic acts strive, as there is a constant strife between the "self" and the "other." The point is that allowing the social status of one's ethnicity and cultural cognition, to determine the way the "other" is perceived, is a way of paving room for xenophobic dominance in a society. Put simply, to navigate the world of the "other" through the lens of one's social status, is problematic, and by implication could lead to a xenophobic attitude.

Pushing the argument for the political causes of xenophobia, Fritzsche opined that prejudices against strangers, could offer an emotional outlet for fear, when both internal and external affairs of a country are unstable (FRITZSCHE 1994, 227-228). Simply put, one can say that the political state of a nation, determines the way such a nation would see strangers. This is because the negative attitudes of government towards those seen as foreigners can be traced to how a state is politically structured. Hence, Navi Pillay notes that:

We should be aware that hatred is not a natural and spontaneous sentiment; rather it is usually the outcome of propagandas and incitements to hate. As seen in the hostility and in the violence that is carried out at several levels including social, media and political spheres. (PILLAY 2012, 3) 
The implication of the above is that xenophobic discrimination is attributable to sentimental incitements, either from the government or other members of the society, a good example is the statement credited to King Goodwill Zwelethini of South Africa, which sparked off the xenophobic violence witnessed in 2015. This is why it is a form of discrimination that is easily stirred up during the times of lack, scarcity and inadequacies. The contention of this paper therefore is that since xenophobia is a menace, there is the urgent need for a reassessment of the conception of the "other", with the ultimate aim of towing an ideal route that could reduce the adverse effects of segregation, hate crime, starvation and even death that are attributable to this menace, since we all inhabit one African continent.

So far, the conceptual analysis of the idea of xenophobia has clearly indicated that xenophobia is a practice that houses quite a number of discriminatory elements. Although it is obvious to note that discrimination as a concept can be given a lot of meanings, this is due to the fact that the usage of the term tends to imply not just the act of creating a level of discrepancy between various individuals or groups (FRITZSCHE 1994, 3), but that it has further meandered its way into becoming a key concept, both in the field of political science, sociology and philosophy. As these disciplines now tend to harbour a number of meaning for the term discrimination, which they now see as a concept that could better capture the state of what transpires within the human society as seen in Africa. Owing to the fact that Africa, over time has been plagued by all forms of discriminatory tendencies, as could be seen in social discriminations, such as racism and even in xenophobic occurrences.

Consequently, Rivas-Drake, Hughes and Way argue that discrimination is usually associated with depression (RIVAS-DRAKE, HUGHES and WAY 2009, 558-584), as there is an inner quest to push the "other" from the "self. It is this inhuman act that gives the understanding of xenophobic discrimination as the act of separating the self from the "other" its sense of meaning. Pointedly, discrimination is an act of segregation, which tries to create the idea of differences amidst a set. It is the act that demarcates or secludes a set of people from others under the guise of possessing certain distinct qualities or attributes (RIVAS-DRAKE, HUGHES and WAY 2009, 556). It follows therefore that the thrust of any discriminatory action, is based on claims such as, "we are different, "they are strangers, "they do not belong here, which are usually utterances that are intended to highlight the distinction amidst the "self" and the other. Thus, the yardstick for the measurement of these acts is the establishment of the idea of difference amidst society.

To this end, the nexus of this work is the establishment of the place of the "other" within the community. This is because discrimination only strife for the inculcation of "otherness" and not "orderliness" into the world. Thus, no matter how Mit chooses to expresses itself, whether as social discrimination, gender discrimination, Ppolitical discrimination and even xenophobic discrimination, the crux of the action is odto separate the "other" from the "self." 


\section{Social Discrimination as a Major Consequence of Xenophobic Tendencies}

Social discrimination is any act of segregation based on the social status of an individual that could either be in terms of pigmentation, education, economic ability, facial features and so on (BOBO and FOX 2003, 319-332). In some cases, social discrimination harbours the same potentiality as racism because racism most often than not, downplays the social status of an individual, based on certain physical or social attributes such as pigmentation, and race. Hence, Lanre-Abass argues that "racism is a doctrine of superiority and inferiority built upon the idea of race, a kind of inferiority that is often used to justify race-based deprivation of benefits, emotional repudiation, moral distaste and perhaps social discrimination (LANREABASS 2010, 364)

Racial discrimination, being a form of social discrimination, has being defined by the International Convention on The Elimination of All Forms of Racial Discrimination (1965) as:

Any distinction, exclusion, restriction or preference based on race, colour, descent, national or ethnic origin, which has the effect of nullifying or impacting the recognition, enjoyment or exercise, on an equal footing, of human rights and fundamental freedom in the political, economic, social cultural or any field of public life. (UNITED NATIONS 1965, NP)

The implication of the above is that racial discrimination implies any distinction against the other, that is based on differences in physical characteristics, particularly racial pigmentation. To this end, Leech defined racism as an ideology and/or structure of action in public sphere, implicitly based on a concept of racial difference as a policy category, which results in both a disadvantage and discrimination for certain racially defined group (LANRE-ABASS 2010). Going by this, racism is thus an ideological construct that assigns a certain race or group of people to a position over others, based on certain physical, social, economic or cultural attributes (MCKINLEY, ROBBINSON, AND SOMAVIA 2001, 2-4).

However, it is quite obvious that social discrimination as exemplified by racism, calls to question, the belief of the equality of every human agent. This is because it tries to draw a dichotomy between various categories of individuals who inhabit the same geographical territory by opening their sight to the claim of difference, which exist between them, using the social elements of race, colour, pigmentation, social status, education and even economic power (MCKINLEY, ROBBINSON, and SOMAVIA 2001, 2). The philosophical concern therefore is that, relating with people under the guise of being the "other" is actually problematic and, $\checkmark$ as such a myopic way of perceiving the "other, would leave behind a level of bias mthat is not needed for the peaceful co-existence of all individuals across the continent Eof Africa.

$\approx \quad$ Thus, to be able to achieve the task of establishing a more robust and inclusive society for all Africans, would require not only jettisoning social 
discrimination, but also entail imbibing and internalising the virtue of tolerance, most importantly tolerating those individuals that have been hitherto seen as the "other" within the society. Tolerance, can serve as a remedy to the problems arising from social discrimination, as it will create space for accommodating the "other (BOBO, and FOX 2003, 319-332). Although it is almost impossible to have any society where all individuals would have the same level of social status, because the human society according to Karl Marx, and Plato is class structured (LAWHEAD 2007, 56-57). Thus, no matter how one strives to eradicate class structure, it however still has a way of getting back to society. This is why, the quest for a more inclusive world, where everyone is accorded his or her rightful place is important. A claim that is premised on the fact that we are all human and naturally, we must necessarily coexist for the good of all.

Another reason, why social discrimination is problematic is that it denies certain individuals of their fundamental human rights. The act of social discrimination, tends to cut off the access of those individuals who are hitherto seen as the "other" from most, if not all of their basic rights, which include freedom of movement, right to life, education, housing, good health and others. These individuals, who are otherwise seen as the "other", now tend to live a life of fear and tension, simply because they are maltreated in the society. This situation should be frowned at because all individuals possess the same basic rights, simply by being human, and as such there is the need to both tolerate and respect the rights of one another. Based on this, John Mbiti's maxim of "I am because we are, and because we are therefore I am (MBITI 1988, 121) hold much weight not only for Africans but also for humanity generally.

Social discrimination is also problematic because it runs contrary to the conception of justice, which requires equal opportunity for all. To this end, LanreAbass argues that achieving equal opportunity for all, is about "levelling the playing ground" or making the competition for resources fair, rather than achieving more equal outcomes (LANRE-ABASS 2010, 369-370). As John Rawls maintains in his work, A Theory of Justice, the liberal principle of distributive justice suggests that there is the need to pacify the adverse outcome of unequal circumstance, by setting out a fair and just means of attaining equal justice (RAWLS 1971, 25-27), by placing all behind the veil of ignorance. The implication of being under this Rawlsian veil of ignorance is that it would give all an equal and fair opportunity when it comes to propounding norms that would affect all members of the society, whether these members are the "others" or the "self", that is whether they are Nigerians, Ghanaians, Gambians or South Africans.

Pointedly, one can quickly note that since social discrimination is bedevilled

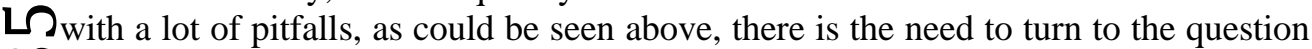
Oof how to either curb or eradicate this menace, thereby making room for a peaceful Esociety. 


\section{Philosophical Implications of Xenophobic Practices for Contemporary Africa State}

Xenophobic discriminations are acts, which could be traceable to a number of factors, a major one of which is the attitudinal and behavioural hostility towards strangers. This affirmation leaves behind a number of philosophical implications. One of such implications is what this paper refers to as epistemic implication. This epistemic problem arises out of the act of bifurcating the "other" from the "self" thereby causing the "other" to be seen as a stranger. The question that follows immediately from this is who is a stranger? Providing an answer to this question would depend on who the question is directed at and as such, an individual would only provide an answer that is permissible to his orientation about the "other" particularly as it relates to who a stranger is. Thus, there is an epistemic challenge of correctly defining the term stranger. Based on this challenge therefore, there is the need to enlighten individuals across societies on the knowledge of the fact that those seen as the "other" are also humans and that no matter where any individual hails from, it is imperative to see such an individual first as a humans and an African, and not as the other. Rene Descartes in The Meditations refers to the human person as any human agent that possesses continuous consciousness overtime and who is therefore capable of representation about the world (DESCARTES 1968, 23).

The above description of the human person is a pointer to the fact that discussion about the human person should be based on the level of rationality and consciousness rather than being premised on any form of segregation against the "other" merely on geographical or social differences. Clearly put, the epistemic certainty of an individual, that is the level of knowledge claim of any individual, must not be limited by economic or social inadequacies rather it should be based simply on the template of their level of rationality in contributing meaningfully to the society. This is why Aristotle's definition of man as a social and rational animal (BOEHNKE 2001, 21-23), and not merely as an individual of a particular race or colour should be embraced as the starting point for the re-assessment of the definition of man, in the context of being called a stranger.

Pointedly, the notion of difference, which is also commonly employed during social and xenophobic discriminations, generates quite a lot of philosophical issues. This is because it carries with it, not only the implication that humanity exists in a world of diversity, but also fails to grant the rightful place of the "other" within such a world. The central challenge with the notion of difference as celebrated in these discriminatory tendencies, is that it does sideline the place of communality and oneness, which happens to be the bedrock upon which most societies, particularly within the African continent is founded. Painting the picture of what an ideal African society should look like, Leopold Senghor, in his work, On African Socialism, argues

Mthat "The Negro-African society is collectivist or more exactly communal, because it ¿ois rather a communion of souls than an aggregate of individuals" (SENGHOR 1964, 249).The implication of this is that the notion of difference upon which xenophobia strives, is both unwarranted and uncalled for, it goes against the spirit of oneness. 
Such a notion is anti-African and by implication anti-Social. There is therefore need to revert to the principles of collectiveness, as captured by Ubuntu and Ujaama in fostering the act of peaceful co-existence among Africans. Also, scholars who are researching within the field of African philosophy must begin to argue for the place of collectiveness since this ideology will possibly contend against the notion of difference. To grant the notion of difference a space in our relation with others is to create a plausible avenue for the disintegration of the communal ideology, which had hitherto been planted in Africa.

\section{Towards a More Inclusive African Society}

Recognising the place of diversity as well as emphasising the awareness, recognition and understanding of human differences requires creating an inclusive environment in which everyone feels esteemed (BERGEN and COLLIER 2013, 87-89). This is based on the fact that human civilisation and social development has brought quite a number of people together, people whose origin and nativity vary one from the other. The point therefore is that the organisational structure of any society whether within or outside Africa is such that cannot be void of the "other" as there is always a way of connecting with the "other" either directly or indirectly, through communication, trade, bi-lateral agreement or even in marriage.

Based on the above summation therefore, it is obvious that the "other" cannot be eradicated from the structure of any society, no matter the level of social and xenophobic discrimination that is meted out on them. Hence, there is the need to turn the quest into how best to improve on interpersonal relationships amidst diverse individuals within our African society. One of such routes would be to advocate the need to imbibe and internalize virtues such as tolerance (BERGEN and COLLIER 2013, 84). Thomas Lickona defines "tolerance" as the ability to accept the values and beliefs of others (LICKONA 2002, 1-3). Similarly, Barry Schwart argues that tolerance is a relatively detached attitude, incorporating the idea of forbearance in which individuals endure the part they found to be offensive in others in order to coexist with others (SCHWARTZ 1996, 24-28). On their part, George Collier and Von Bergen, defines tolerance as civility which falls somewhere between forbearance and acceptance (BERGEN AND COLLIER 2013, 87-89). Finally, article one of the United Nations Educational, Scientific and Cultural Organization (UNESCO) declarations on tolerance (1995) has it that:

Tolerance is respect, acceptance and appreciation of the rich diversity of our world's culture, our form of expression and ways of being human. It is fostered by knowledge, openness, communication and freedom of thought, conscience and belief. Tolerance is harmony in difference. It is a moral duty; it is also a political and legal requirement. Tolerance the virtue that makes peace possible contributes to the replacement of the cultures of war by the cultures of peace... (UNESCO 1995, NP) 
The above definition of tolerance, presents a holistic description of the concept, as it presents tolerance not only as a virtue, but also as a duty - a moral duty at that. This means that one must necessarily tolerate the other not because of any impending consequences for not doing so, but rather because such an act is morally required of such an individual. This idea is better captured in the categorical imperative of Immanuel Kant (LAWHEAD 2007, 56-57). Recall, that Kant regarded the categorical imperative as the supreme moral principle, and in formulating this principle he propounds a moral system where reason is assigned its proper role of legislating our actions (UDUIGWOMEN 2006, 55). The basic notion behind the Kantian categorical imperative is that a moral action is that action performed purely on the basis of duty, which rules out self-interest, inclination or emotion.

Synthesising the above arguments is to maintain that tolerance is a necessary ingredient for resolving the plight of social discrimination and xenophobia. Also, the ideology of tolerance tends to bridge the gap between the "other" and the "self, thereby creating a more inclusive society. While it is pertinent to note that tolerance is more than merely respecting the rights of others, it also entails allowing the "other" to think, act and see things distinctly (BERGEN AND COLLIER 2013, 8789). It demands that every ideology, value claim or personal ideologies must be accorded their rightful place in the league of humans. Pointedly, the idea of tolerance propagates the idea of "acceptance", an accommodative way of seeing the society outside the individual. Hence, it seeks to maintain that beyond the obvious differences across societies, there is still a way of making individuals co-exist peacefully by simply letting the "other" have their rightful place (BERGEN AND COLLIER 2013, 87-89).

Lending credence to the above, Kreeft Peter holds that tolerance is an essential quality in any society as it is one of the basic non-controversial values that are essential for peaceful co-operation among members of a society (KREEFT 2007, $\mathrm{NP}$ ). Hence tolerance is a needed tool against all forms of discriminations within Africa. Tolerance will give room for peaceful co-existence between men even in situations of scarcity, lack or even plenty. If human beings are to be regarded as worthy of dignity regardless of whether their values differ or not, then, there is need to grant tolerance its rightful place in our social relation with the other. For this would make everybody by virtue of being human qualify for the status of possessing dignity which had been earlier deprived of the "others", due to the social cum racial discriminations in society. The point therefore is that to achieve a greater selfunderstanding of the other is a feat that must be accomplished through the lens of tolerance. This is because Africa as a continent could enjoy better peace when all its stakeholders imbibe the virtue of tolerance.

The implications of the above discussion thus far is that injecting order into Many disordered society would require erasing the idea of "other", for there can hardly odbe order in any society where citizens do not tolerate the other. Hence, replacing the Eclamour for "otherness" with that of "orderliness" would be a right step in the right direction. This would help to reduce the various forms of civil unrest that is 
witnessed across the various countries within African today. The point still remains that the outcome of the xenophobic violence in South Africa in the year 2015 could have been avoided if only tolerance was allowed to inscribe the mark of orderliness into that society.

While it is clear that there is an increasingly high rate of intolerance, social and xenophobic discrimination, insurgency and war in some countries across Africa, which has however contributed to the hindrance to peace and development, it is still pitiable that the various governments of these countries have not being able to curb this menace. Injecting peace into any society must begin with an advocacy for the act of tolerating one another. This, must be carried out with the help of all the agents of socialisations namely, family, schools, mass media religious organisations and a host of others. These social institutions could play a vital role in the teaching of how to imbibe the virtue of tolerating one another. If individuals can respect the rights of "others", both to have and to express themselves in the world irrespective of where they are from, then the world would be a step closer to living in a truly charitable and peaceful continent.

\section{Conclusion}

Thus far, this paper has examined the place of tolerance in the quest to curb social and xenophobic discrimination in Africa. It maintained that these forms of discrimination happen to be the major menaces which have befallen the current day contemporary African society; a position that now stresses "otherness" rather than "orderliness" in the composition of these states. Consequently, the paper presented arguments to show that these forms of discrimination bifurcates human society thereby creating the "we" and the "them". The thrust of the paper however had been on how best to return the African society to its original more accommodative, communal, collective and encompassing state. This, the paper believes, can be achieved if people internalize the virtue of tolerance particularly in the way and manner that individual across the African continent relate with one another. The point therefore is that orderliness in the midst of a turbulent world is still possible and attainable.

\section{Relevant Literature}

1. BOBO, Fox. "Race, Racism and Discrimination: Bridging Problems, Methods and Theory in Social Psychological Research." [Social Psychology Quarterly], Vol. 66, Pp. 319-332, 2003. Web.

BERGEN, Von and Collier, George. "Tolerance as Civility in Contemporary Workplace Diversity Initiatives." [Administrative Issues Journal], Vol. 3, No.1, Pp. 48-62, 2013. Web. 
3. BOEHNKE, Klaugu. [International Migration, Xenophobia and Policy Challenges for Regional integration in South Africa], 2001. SAMP: Pretoria. Web.

4. BRUDER, Kenneth and Moore, Brooke. [Philosophy: The Power of Ideas, $8^{\text {th }}$ edition], 2011. McGraw-Hills: New York. Paperback.

5. CRUSH, Jonathan Ed. [Xenophobic Violence in South Africa: Denialism, Minimalism and Realism], 2014.Cape Town: SAMP. Paperback.

6. DESCARTES, Rene. [Meditations on First Philosophy, E. S. Haldene and G.R.T Ross, Trans.], 1968. Cambridge University Press: Cambridge. Paperback.

7. FRITZSCHE, Ken. "Conditions for Xenophobia in Eastern Germany." [Nationalism, Ethnicity and Identity: Cross National and Comparative perspective, R. F. Farnen. Ed.] 1994. Transaction: Edison NJ. Paperback.

8. LANRE-ABASS, Bolatito. "Racism and its Presuppositions: Towards a Pragmatic Ethnic of Social Change." [Human Affairs], Vol. 20, No. 4, Pp. 39-55, 2010. Paperback.

9. LICKONA, Thomas. "Making Sense of Tolerance and Diversity." [The Fourth and Fifth RS], Vol. 8, Nos.1-3, Pp. 617-639, 2002. Web

10. MBITI, John [African Religions and Philosophy], 1988. Heineman books: London. Paperback.

12. MCKINLEY, Bruson Robbinson, Mary and Somavia, Juan. [International Migration, Racism, Discrimination and Xenophobia], 2001. UNESCO: Geneva. Web.

13. OKSANA, Yakushko. "Xenophobia: Understanding the Root and Consequences of Negative Attitudes Towards Migrants." [The Counseling Psychologist], Vol. 37, No.1, NP, 2009. Web.

14. PILLAY, Newton. "Xenophobia." [United Nation High Commission for Human Right Document], Pp. 265-282, 2012. UN: Geneva. Web.

RAWLS, John. [A Theory of Justice], 1971. Harvard University Press: Cambridge. Paperback. 
Filosofia Theoretica: Journal of African Philosophy, Culture and Religions

16. REYNOLD, Fold and Ian Vine. [The Socio-Biology of Ethnocentrism: Evolutionary Dimensions of Xenophobia, Discrimination, Racism and Nationalism], 1987. Carom Helm: London. Ebook

17. RIVAS-DRAKE, D. Hughes, and N. Way. "A Preliminary Analysis of Associations among Ethnic-Racial Socialization, Ethnic Discrimination and Ethnic Identity among Diverse Urban Sixth Graders.'[Journal of Research on Adolescence], Vol. 19, NP., 2009. Web.

18. SCHWARTZ, Thomas. "Tolerance: Should we approve of it, Put up with it or tolerate it?" [Academe], Vol.82, No.1, Pp. 317-334, 1996. Web.

19. SENGHOR, Leopold [On African Socialism, Mercer Cook. Trans.] 1964. New York; Blackwell. Paperback

20. SUAREZ-OROZCO, Cambell. [Transformation: Immigration, Family Life and Achievement among Latino Adolescents], 2005. Palo Alto: Stanford. Web

21. UDUIGWOMEN, Andrew. [Introducing Ethics: Trends Problems and Perspectives], 2006. Calabar: Jochrisam Publishers. Paperback

22. UNITED Nations. [The International Convention on the Elimination of All Forms of Racial Discrimination], Web. Retrieved on September 20th, 2015.

23. UNESCO. [Declaration of Principles on Tolerance], 1995. Web. Retrieved on September 20th, 2015.

24. ZWELITHINI, Goodwill. "Foreigners must go Home-King Zwelithini." Web. Retrieved in October, 2015. 